school entry a test of visual acuity is recommended (repeated at three yearly intervals), and a colour vision test between 9 and 13. At present - however desirable would be the aim of preventing amblyopia-we have no suitable screening method for early detection. Much research needs to be done before we can be confident that vision screening programmes can prevent amblyopia.

The ability correctly to diagnose sensorineural hearing losses at an early stage has been regarded as a useful indicator of the effectiveness of child health services. Distraction testing at 6 to 8 months has been regarded as the means for achieving this. The test requires a high level of skill and good conditions if valid results are to be obtained. Modern technological innovations in neonatal screening such as the auditory response cradle have not solved all the problems, ${ }^{16}$ and parental observations may continue to be better than any clinical skill or technological advance. ${ }^{1718}$ The report recommends screening in the first year of life using the distraction test, a universal screen at school entry, and a service that is responsive to parental concerns. The importance of adequate diagnostic facilities to follow up screening tests is emphasised.

"Developmental screening" has become an invention of the generations of developmental paediatricians since the sequence of normal development was described. ${ }^{19}$ These descriptions were translated into scales of normal and abnormal development and applied to whole populations of children. The wide variation of "normal," the difficulty of showing it, and the poor predictive value of early developmental tests have resulted in a system with false positives and negatives. The commonsense solution - to rely on and respond to parental observations - has now been endorsed by this report, supported as it is by an increasing body of research results. $^{67}$ Those carrying out surveillance of children's development will need to move away from their crayons and one inch cubes and cultivate new skills in history taking and observation.

This report shows us what we have learnt about child health surveillance. We have learnt what we do not know. The "biblical" method of assessment - "he looked at it and saw that it was good" - is no longer an adequate means of determining what should be the content of our programmes. Much research remains to be done. What we are sure of we should do well, with full awareness of the importance of our partnership with parents. The time released by doing less, but doing it well, can be well used in the next stage of providing help for those children and families whose needs are identified by the programme.

Senior Lecturer in Child Health,

LEON POLNAY

University of Nottingham,

Queen's Medical Centre,

Nottingham NG7 2UH

1 Lane-Clayton JE. The child welfare movement. London: G Bell and Sons, 1920.

2 Subcommittee of the Standing Medical Advisory Committee, Child Welfare Centres. Report. London: HMSO, 1967. (W Sheldon, chairman.

$3 \mathrm{Hall} \mathrm{DMB}$, ed. Health for all children, the report of the joint working party on child health surveillance Oxford: Oxford University Press, 1989

4 Hall DMB, Hall SM. Early detection of visual defects in infancy. Br Med $\mathcal{F}$ 1988;297:723-4.

Hitchings U, Haggard MP. Incorporation of parental suspicions in screening infants. Br. $\mathcal{A}$ Audiol 1983;17:71-5

6 Nicol A, Mann N, Mann J, Vyas H. The child health clinic: results of a new strategy of community care in a deprived area. Lancet 1986; ; 606-8.

Sonnander K. Parental development assessment of 18 month old children: reliability and predictive alue. Dev Med Child Neurol 1987:29:351-62.

8 De Swiet M, Dillon MJ, Littler W, O'Brien E, Padfield PL, Petrie JC. Measurement of blood pressure in children. Recommendations of a working party of the British Hypertension Society. Br.Med f 1989;299:497.

9 Hill RR, Standon PJ, Tattersfield AE. Asthma, wheezing and school absence in primary schools. Arch Dis Child 1989;64:246-51.

10 Grindulis $\mathrm{H}$, Scott PH, Belton NR, Wharton BA. Combined deficiency of iron and vitamin D in Asian toddlers. Arch Dis Child 1986;61:843-8.

11 Aukett MA, Parks YA, Scott PH, Wharton BA. Treatment with iron increases weight gain and psychomotor development. Arch Dis Child 1986;61:849-52.

12 Griffiths PD, Mann JR, Darbyshirc PJ, Green A. Evaluation of eight and a half years of neonata screening for haemoglobinopathies in Birmingham. Br Med 7 1988;296: 1583-5.

13 Ingram RM. Amblyopia. Neither screening nor treatment is satisfactory. Br Med f 1989;298:204.

14 Shaw DE, Fielder AR, Marshall C, Rosenthal AR. Amblyopia-factors influencing age of presentation. Lancet 1988;ii:207-9.
15 Johnson A Stayte M, Warthan C. Vision screening at 8 and 18 months. Br Med 7 1989.299.515-9. 16 McCormick B, Curnock DA, Spavin I. Auditory screening of special care neonates using the McCormick B, Curnock DA, Spavin I. Auditory screening
auditory response cradle. Arch Dis Child 1984;59:1168-72.

17 Curnock DA. The senses of the newborn. Br.Med $f$ (in press).

18 Martin JAM. Childhood deafness in the European Community. Brussels: Commission of the European Community, 1979.

19 Gessell R. Studies in child development. New York: Harper and Row, 1948.

20 Sheridan M. Children's developmental progress. Windsor: National Foundation for Educational Research, 1973

\section{"Health for All Children" and the new contract}

The new report Health for All Children, outlined by Dr Polnay in the previous article, is a consensus view on the nature and purpose of a child health surveillance programme. The issue of how such a programme should be delivered is, however, still unresolved.' For many years community doctors, health visitors, and general practitioners have contested the ownership of child health surveillance. ${ }^{2}$

A flexible approach to child health surveillance is desirable, with an emphasis on preventive work, guidance, and support to parents. Resources should be directed to those parents who need them most. Yet the programme as described in the new report contains only a few checks and screening tests that require skills unique to doctors - specifically, the examination at six weeks and some later physical checks that can be carried out on an opportunistic basis.

The new contract for general practitioners suggests that family practitioner committees should admit "suitably trained" doctors to a list of doctors prepared to carry out a child health surveillance programme planned and approved by the health authority. ${ }^{3}$ Its authors presumably supported the view that a child's development and health are intimately related to the health of the whole family and are therefore properly part of family medicine. But several questions remain.

Firstly, why does the contract not specify more precisely the content of the child health surveillance programme? Perhaps the authors reasoned that it would be undesirable to specify an identical programme for all children and for all areas of the country. A second and more puzzling question is the level of remuneration implied in the illustrative examples in the appendix of the new contract; they suggest that the capitation fee payable for child health surveillance may be only about one quarter of the maximum immunisation fee. Many general practitioners may feel that this would be inadequate to compensate for the further training required or for the investment of time. This will certainly be the case if the health authority or board specifies a complex programme that includes several detailed development examinations and must be delivered in its entirety by the general practitioner in person.

If, on the other hand, general practitioners are required to carry out only those checks that require physical examination, this service might be provided at the same time as other preventive health care activities such as postnatal checks and immunisations. General practitioners who achieve a high immunisation uptake may easily earn the extra income for child health surveillance. Conversely, general practitioners who do not offer a child health surveillance service may find their immunisation income seriously reduced because children who attend community clinics for health checks will also be likely to receive immunisations there.

Authorities and boards adopting this approach will need to provide the remainder of the surveillance programme by other means, and health visitors would be the obvious choice. Their training is oriented increasingly to health promotion and preventive care; they have access to the home more readily than do most other professions; and they have 
opportunities to observe the family as a whole. Nevertheless, a successful surveillance programme can be provided by health visitors only if they receive continuing professional education and support in all aspects of child development. Close working relationships with individual general practitioners and community paediatricians would be essential. The general practitioner would accept responsibility for the organisation of child health surveillance within the practice and would offer advice or arrange referrals as appropriate.

What training should be required of general practitioners who wish to participate in child health surveillance? A national consensus has yet to emerge on this issue. It is doubtful whether any existing postgraduate qualification is sufficient evidence of the necessary knowledge and skills. Perhaps certification could be arranged as an option during vocational training, as is already the case with family planning. Despite the present uncertainty, however, three requirements may be identified.

Firstly, though general practitioners do not need to undertake developmental examinations, they must have some insight into the process of child growth and development and the problems that affect it. Perhaps more important are respect for the anxieties raised by parents and other professionals and readiness to refer children promptly for more expert assessment. The training requirement could be fulfilled by private study and suitable short courses. Secondly, many general practitioners will also welcome individual instruction in physical examination techniques and in normal child development. This training can most conveniently be offered by local clinicians. The third essential is a detailed statement of the surveillance policy adopted by each individual health authority or board. This should be accompanied by information about the optimal referral pathways for children with suspected developmental or health problems.

The new contract recognises that general practitioners will need to supply information about which children have been examined so that the surveillance programme can be monitored in each health district. Few districts have the means to do this; and though "information technology" offers various solutions, all require substantial planning and investment. No doubt specialists in community medicine and directors of public health will wish to take part in these developments.

What is the future for community child health doctors? As not all general practitioners will wish to offer a child health surveillance service, many parents will continue to attend community clinics for checks and advice, particularly in socially deprived areas, where the standard of general practice is sometimes low. The need for these clinics will, however, probably diminish as more general practitioners take up the challenge of practice in these areas.

Only a few general practitioners will have either the desire or the opportunity to become expert in diagnosing developmental disorders. Community doctors, who have a wider experience of child development and behaviour, should therefore extend their consultative role, but they will need further training, better supervision, and greater credibility. These improvements are most likely to be achieved if community doctors have a consultant led service, a planned career structure, and a closer association with hospital departments of child health.

D M B HALL

Consultant and Honorary Senior Lecturer in Community Paediatrics, St George's Hospital and Medical School,

London SW17 0QT

\footnotetext{
1 Hall DMB. Health for all children: a programme for child health surveillance. Oxford: Oxford University Press, 1989

2 Butler J Child health surveillance in primary care: a critical review. London: HMSO, 1989.

3 Department of Health and Welsh Office. General practice in the National Health Service. A new contract. London: $\mathrm{DoH}, 1989$.
}

\section{Patients with spinal injuries}

\section{Early transfer to a specialist centre is vital}

In the past 50 years the greatest advance in managing patients with spinal cord injuries has been the establishment of trauma services for the complete care of such patients. Most spinal injuries units in Britain, however, developed with no account being taken of national planning. As a result their distribution is far from ideal and some areas (such as Kent) remain ill served.' Ideally, patients with spinal injuries should be admitted to the nearest unit within 24 to 48 hours of their accident, but this is not always achieved. ${ }^{23}$ The opening of the Duke of Cornwall Spinal Treatment Centre in Salisbury in January 1984 provided the stimulus for us to look at the pattern of treatment and transfer of such patients in the south and south west of England.

No clear guidelines have been agreed for optimum management, and consequently some patients have experienced considerable delay in admission to the centre. Only $37 \%$ of patients who had been treated conservatively and $4 \%$ of those who had undergone a stabilising operation before transfer were admitted to the centre within 48 hours after injury. In those who had been operated on the commonest reasons for delay were related to spinal operations and their complications (36\% of patients). Nine per cent of patients underwent multiple transfers, being moved firstly to a hospital where spinal surgery was available and then to the spinal treatment centre.

One of the serious complications caused by the delay was the development of pressure sores. No sores were seen in patients admitted within 48 hours after injury, but if transfer was delayed by eight days or more the incidence of pressure sores was $14 \%$ in patients who had been treated conservatively and $29 \%$ in those who had had an operation.

Other complications of operations were also common. Some of these were the result of inappropriate treatment that was given because doctors, often failed to understand the pathophysiology of the injury, and others resulted from technical failure - inadequate bone grafting or inappropriate spinal instrumentation. Thirdly, some problems seemed to be due to lack of skills in the use of spinal instrumentation. These technical failures made a further operation necessary in 15 out of 77 patients $(19 \cdot 5 \%)$

Our analysis of all of the patients who had both primary and revision operations in the spinal treatment centre showed a rate of complication of zero. These patients were treated by rigid spinal immobilisation by using either a posterior approach with interspinous wiring in the cervical spine or square ended contoured Harrington rods with bifid upper hooks in the thoracic and thoracolumbar spine. Every patient had extensive bone grafting and was supported postoperatively in a firm cervical collar or brace. Only one patient asked for the internal stabilisation device to be removed because of an extremely active lifestyle. No patient deteriorated neurologically after surgery, but neurological benefit was not analysed - the numbers were too small and no attempt was made to randomise treatment.

We believe that if surgeons are to avoid the many potential pitfalls in operating on patients with acute spinal injuries the initial appraisal should be made a by team of doctors who are fully conversant with the modern techniques of stabilisation and instrumentation. Doctors at the district hospital where the patient is treated initially should, we believe, consult with the nearest supraregional spinal unit so that joint decisions 